\title{
Intergovernmental Fiscal Transfers and Equalization
}

\author{
Nils Soguel
}

\subsection{INTRODUCTION}

It is extremely rare for Swiss institutions to undergo a revolution. And yet for the last ten years, the fiscal transfer and equalization system (Finanzausgleich; péréquation financière) between the Confederation and the cantons have been reformed so much that it can rightly be considered a revolution. And even more so, because most cantons followed suit and transformed their own fiscal transfer and equalization systems with their municipalities based on the federal model.

These changes came about in a context in which certain elements of Swiss federalism were, and still are, being debated: the elements include the degree of decentralization that is desired, the prevention of negative incentives in economic development, and adverse selection phenomena in the jurisdictions where redistribution is the most generous.

The author is grateful to Yves Ammann for his contribution to this chapter.

N. Soguel $(\bowtie)$

IDHEAP, University of Lausanne, Lausanne, Switzerland e-mail: nils.soguel@unil.ch

(C) The Author(s) 2019

A. Ladner et al. (eds.), Swiss Public Administration, Governance and Public Management, https://doi.org/10.1007/978-3-319-92381-9_17 
This chapter briefly surveys how the transfer systems are organized, and describes their benefits and shortcomings. ${ }^{1}$ Though fiscal transfer and equalization reform generally include revising the division of tasks between fiscal tiers, this will not be discussed here. The following sections first discuss the design of the national fiscal equalization (Sect. 17.2) and then discuss where it can be improved (Sect. 17.3). Section 17.4 focuses on the financial dependence of the Swiss cantons on transfers which largely come from the central government. Sections 17.5 and 17.6, respectively, briefly present the design of the different cantonal fiscal equalization systems, and where there is room for improvement.

\subsection{Design of the National Fiscal Transfers AND EQUALIZATION}

The revised national fiscal transfer and equalization system, and the division of tasks between the Confederation and the cantons, came into effect in 2008. To the extent that the revision necessitated modifying laws and the Constitution, Switzerland's method of direct democracy required that these be approved by both the majority of Swiss citizens and by a majority of the cantons. The modifications were subjected to popular referendum on November 28, 2004, and were approved by nearly $65 \%$ of the voters and 23 of the 26 cantons. The three which rejected the project were all cantons which would become net payers (Nidwalden, Schwyz, Zug).

The new system corrects several weaknesses in the previous system. The previous system was designed to achieve two goals when the Confederation made a financial transfer to a canton. One goal was to at least partly compensate a canton for the costs it had to bear when carrying out tasks that benefitted the Confederation (cost compensation; Lastenausgleich; compensation des charges). But transfers were simultaneously also intended to make additional financial resources available to cantons considered financially weak (resource equalization; Ressourcenausgleich; péréquation des ressources).

\footnotetext{
${ }^{1}$ Financial transfers between governments fit the more general definition of transfers: "a transaction in which one institutional unit provides a good, service, or asset to another unit without receiving from the latter any good, service, or asset in return as a direct counterpart. This kind of transaction is also referred to as being unrequited, a 'something for nothing' transaction, or a transaction without a quid pro quo. Transfers can also arise where the value provided in return for an item is not economically significant or is much below its value" (IMF 2014, p. 41).
} 
Transfers often were earmarked and came in the form of matching grants. For example, the Confederation gave grants to cantons for the construction and maintenance of highways. Financially stronger cantons were given grants at rates as low as $40 \%$ (of the corresponding costs), while the weakest cantons had rates of nearly $90 \%$. Nevertheless, these kinds of equalizing supplements (which in this case could vary by as much as $50 \%$ points) had not made it possible to reduce resource differences between the cantons. Additionally, in the previous system the cantonal tax burden was included in computing a cantons' fiscal capacity. Fiscal capacity was used to calibrate the equalizing supplement as well as federal revenue sharing with the cantons (notably $13 \%$ of the federal income and profit tax). Given the cantons' significant tax autonomy, it is not surprising that the cantons tried to manipulate their tax burden in order to maximize the grant they received from the central government.

The new scheme no longer attempts to kill two birds with one stone; one reason is that it is now based on two key pillars. In the first pillar, the main goal is to equalize financial resources across the cantons. The second pillar is meant to compensate cantons for the cost incurred in various areas.

The Federal Act on Fiscal Equalization and Cost Compensation (Bundesgesetz über den Finanz- und Lastenausgleich; Loi fédérale sur la péréquation financière et la compensation des charges) designates the relevant constitutional provisions. Its Article 2 states that the goals of the equalization scheme are to "strengthen the financial autonomy of the cantons" and "decrease differences in terms of fiscal capacity and tax burden" between them. Indeed, the 26 cantonal governments are far from being on equal footing in providing their respective populations with public services. They face quite different economic situations. As a result, the tax base differs substantially and obliges "poorer" cantons to place a higher tax burden on their citizens. Also, their respective population structures or geographic situation generates differing needs and costs in providing the requisite public services.

\subsubsection{Resource Equalization}

Resource equalization is the most important pillar of this scheme. It is specifically designed to help out the financially weaker cantons, that is, those that have a lower potential for fiscal resources stemming from their own local economy. Equalization relies on an estimate of the resource 
potential (Ressourcenpotenzial; potentiel de ressources) per capita for each canton. The potential is determined by an aggregation of the tax bases of the different taxes levied by the cantons. Essentially, it means adding together the effective taxable resources, something which cannot be directly influenced by the cantons, at least in the short term.

Comparing the per capita cantonal potentials to the Swiss average creates a resource index (Ressourcenindex; indice de ressources). Cantons with a score higher than $100 \%$ of the average contribute to the equalization, while those with a score lower than $100 \%$ receive equalization funds. Figure 17.1 presents the index for 2018, which shows that three-fourths

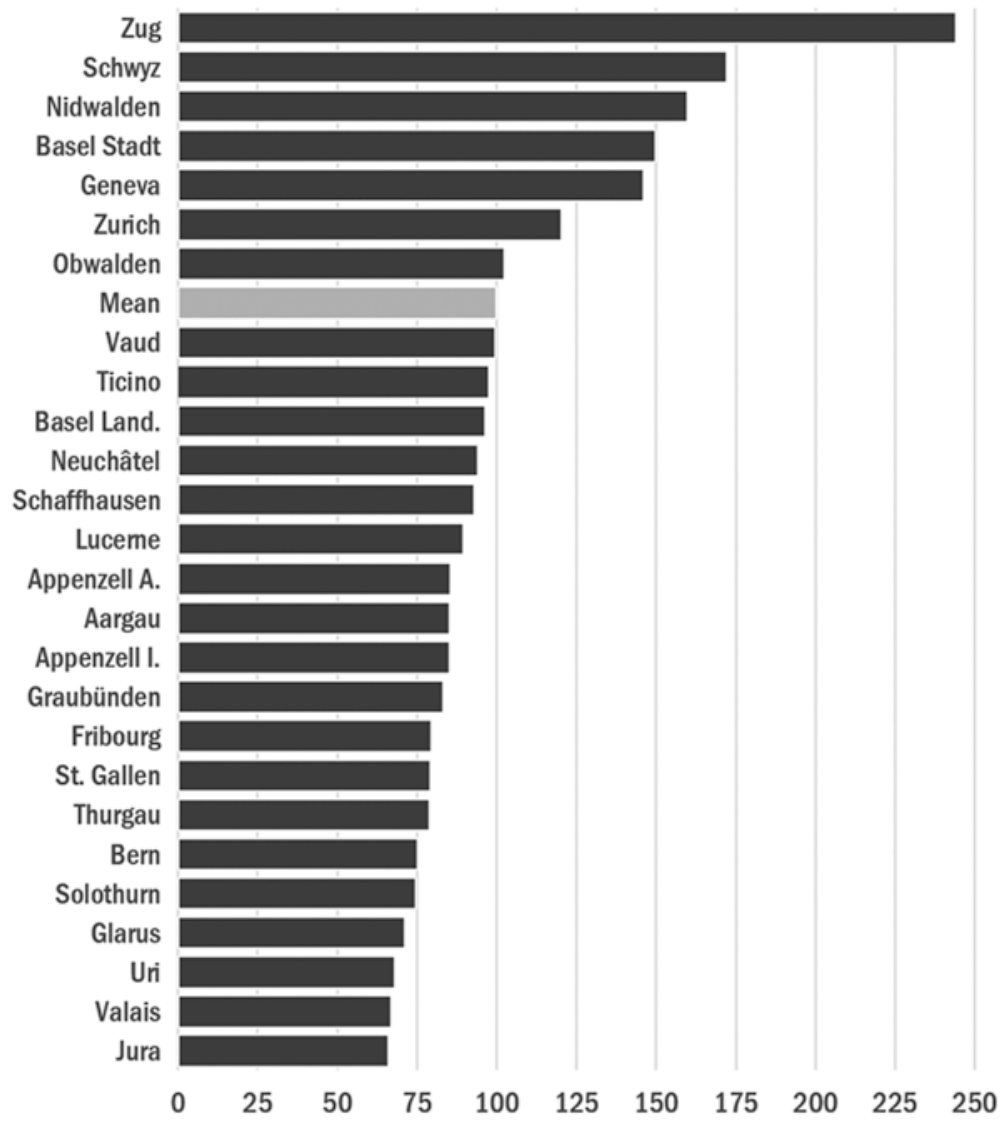

Fig. 17.1 Resource index, 2018. (Source: Federal Finance Administration) 
of all the cantons have a lower score than the average. The weakest canton (Jura) has only $66 \%$ of the average; the strongest (Zug), 244\%.

Figure 17.2 illustrates the significance of the redistribution effects national financial equalization creates by showing the polar cases: one in which equalization would have no redistributive effect and one in which the effect would make resources completely uniform across all the cantons.

In the Fig. 17.2, the resource index before equalization (i.e., corresponding to the canton's own potential) is shown on the horizontal axis; the index after equalization is shown on the vertical axis. Imagine that the

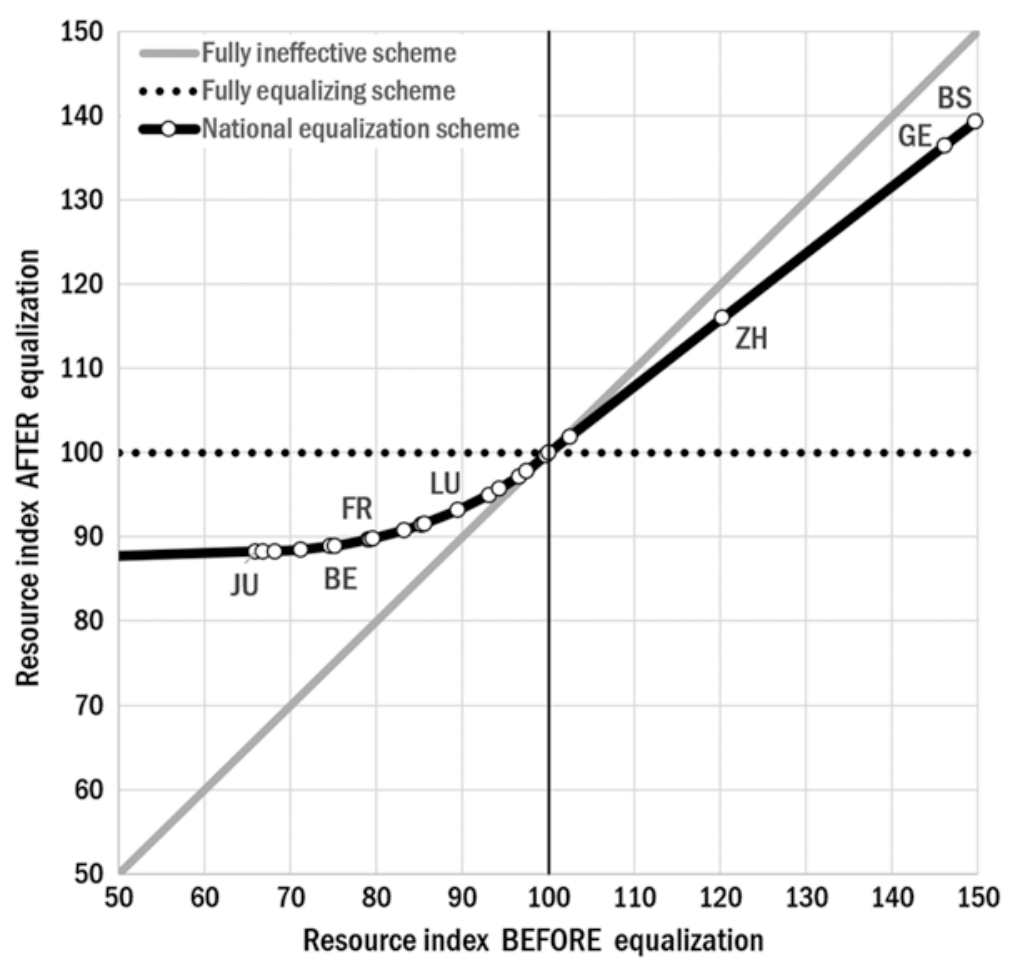

Fig. 17.2 National equalization scale, 2018. (Note: JU, Jura; $B E$, Bern; $F R$, Fribourg; $L U$, Lucerne; $Z H$, Zurich; GE, Geneva; and $B S$, Basel Stadt. In order to improve the readability of the chart, the values for the three financially richest cantons are not displayed: Nidwalden (Index was 160 before and 147 after equalization), Schwyz (172 and 157), and Zug (244 and 214). Source: Federal Finance Administration) 
equalization scheme would be completely ineffective: the values would remain the same both before and after (gray line). No redistribution would take place, and the weaker cantons would remain weak (e.g., with an index of 80 ), whereas the "strong" would remain strong (e.g., at 120).

The opposite is depicted by the horizontal dotted line: a fully equalizing scheme where the resources of the strongest cantons are reduced to such an extent that after equalization, their resources would only amount to $100 \%$ of the national average. The weaker cantons would receive grants that would bring them up to the 100 mark after equalization. Regardless of the situation before equalization, all cantons would have the same resource levels per capita after equalization.

The national equalization system, represented by the dark solid curve, lies between these extremes: a few cantons are indicated for the sake of readability. The scheme guarantees a minimum allocation of about $85 \%$ after equalization (Mindestausstattung; dotation minimale), so that the canton with the lowest index (Jura, JU) before financial equalization receives enough transfer payments so that its index afterwards reaches $88 \%$. Among cantons shown in the figure, the canton with the highest index before (Basel Stadt, BS), at $147 \%$, is still at $137 \%$ after equalization. (Not displayed are the cantons that have even a higher index values, namely $\mathrm{ZuG}$, Schwyz, and Nidwalden, all three cantons which voted against the reform) The equalization rate is thus regressive for the weakest cantons (i.e., an increase in their own potential corresponds to a decrease in the amount of transfer they receive) and becomes proportional for the strongest cantons: the amount they have to pay is a fixed percentage of the difference between their index and 100.

Fiscal equalization is not only financed by the fiscally strongest cantons. It is also financed by the central government. In 2018, the Confederation paid in 2.42 billion CHF ( $0.36 \%$ of gross domestic product (GDP)) and the seven financially strong cantons paid in 1.65 billion CHF $(0.24 \%)$; and the 19 weakest cantons received 4.07 billion $\mathrm{CHF}$.

Compared to the former equalization scheme, the reformed system incorporates horizontal transfers, although the vertical transfers are still larger. Also, grants are no longer earmarked, and the receiving cantons can freely allocate them as if they were their own resources.

\subsubsection{Cost Compensation}

The cost compensation scheme is meant to help the most urbanized cantons as well as the mountain cantons; each face-if for quite different 
reasons - structurally higher costs. Only costs necessary to provide the population with the public services for satisfying their basic needs are compensated, and in principle, only for the part of the cost that exceeds "normal" cost. Thus, public spending that goes beyond basic needs and reflects specific cantonal preferences are, in principle, not compensated. Spillover effects between jurisdictions also are not compensated within the national scheme. ${ }^{2}$

The compensation here involves two types of costs incurred by the cantons. Some cantons-especially the more urbanized-face higher needs, and thus costs, due to socio-demographic factors. Amounts allocated to these cantons are based on the incidence of poverty, age structure, integration of foreigners, and urbanization. Other cantonsespecially the more mountainous and rural ones-face higher costs due to geo-topographical factors. Amounts allocated here are based on altitude, slope of the terrain, structure of the habitat, and population density.

This form of compensation is financed entirely by the central government, and so these transfers are uniquely vertical. In 2018, the Confederation paid in 0.72 billion $\mathrm{CHF}(0.11 \%$ of GDP), with half going to the first group of cantons (for socio-demographic reasons) and half to the second group (for geo-topographical reasons).

\subsubsection{Compensation for Hardship Cases}

Compensation for hardship cases rounds out the two pillars of the scheme (Härteausgleich; compensation des cas de rigueur). This was introduced to alleviate the financial loss experienced by the financially weaker cantons when the former fiscal equalization scheme was reformed. The compensation declines by $5 \%$ per year and is expected to expire completely by 2036 . It is allocated exclusively to financially weak cantons, and the need for it is reviewed at regular intervals. In 2018, only six cantons qualified and 0.30 billion CHF ( $0.04 \%$ of GDP) was transferred; two-thirds of the money comes from the Confederation and one-third from the cantons.

\footnotetext{
${ }^{2} \mathrm{~A}$ canton that provides public services benefiting the population of other cantons can receive compensation for the corresponding costs in the specific context of an intercantonal collaboration and outside the national transfer system.
} 


\subsection{Room for Improvement in the National Equalization System}

According to a recent evaluation by the Federal Council (2014), national fiscal equalization contributed to a notable reduction in intercantonal disparity, and it exhibited no serious flaws. Furthermore, as the Organization for Economic Co-operation and Development (OECD) (2015) pointed out, the established equalization system made it possible to significantly mitigate the effects of tax competition between the cantons.

But there is a downside. The current scheme reduces, or even obliterates, any incentive for the financially weakest cantons to develop their own resource potential. In essence, in the cantons in which the resource index is lower than $85 \%$, each ten-franc increase in resource potential per capita is, on average, compensated by a decrease of eight $\mathrm{CHF}$ in equalization transfers (Federal council 2014). One proposal would then be to reduce this marginal clipping rate (Grenzabschöpfungsquote; taux d'écrêtage marginaux) of $80 \%$.

A second problem comes from how the tax bases of the different taxes are aggregated to estimate the resource potential. A simple addition is not possible since the wealth tax base is much larger than the income tax base, for example, and the tax rates are markedly different. This makes it necessary to weight the tax bases to account for their respective contributions to the resource potential, but this involves an element of arbitrariness and reduces the transparency of the system. Additionally, it impacts the incentive given to the cantons to attract new companies. Putting a smaller weight on company profits when calculating resource potential should solve this problem while limiting the rise in revenue potential.

Third, vertical equalization is always much larger than horizontal equalization: 3.34 billion CHF currently, about two-thirds of the total. Yet vertical equalization is less effective at correcting inequalities because it benefits the financially weaker cantons without much affecting those cantons which are financially strong. Put differently, horizontal equalization has a positive effect on the weak and a negative effect on the strong.

Finally, only a small number of cantons contribute to horizontal resource equalization. The numbers mean that cantons which benefit have more political power to defend their gains or to demand an increase in equalization transfers. This certainly made it easier for referendum on the reform to be passed (as a majority of the cantons had to be in favor), but the contributing cantons increasingly feel that they are being subjected to the tyranny of the majority. 


\subsection{Cantonal Dependency on Transfers}

In 2018, the national system involves transfers amounting to 5.09 billion CHF (4.07 billion CHF in resource equalization +0.72 billion $\mathrm{CHF}$ in cost compensation +0.30 billion CHF in hardship compensation). Although this amount seems large, it is only $0.75 \%$ of GDP. We can thus conclude that the cantons are not very financially dependent on this type of transfer, as Fig. 17.3 corroborates. Across all 26 cantons, equalization transfers are only $6 \%$ of all revenue. There is, however, a notable difference between cantons which receive next to nothing (e.g., Basel-Landschaft) and cantons in which the equalization transfers constitute more than $20 \%$ of their revenue (e.g., Uri).

The cantons can also count on transfers outside the national equalization scheme, especially vertical ones. In essence, the Confederation sends cantons compensation (Entschädigungen; dédommagements) when they provide public services for which the Confederation is legally responsible. In this case, the cantons are considered to be implementing agencies. The Confederation also provides contributions to cantons (Beiträge; subventions or contributions) to incentivize them to provide public services for which cantons are themselves responsible. Both compensations and contributions are specific grants, since the purposes for which they may be used is defined by the central government. These specific vertical transfers on average amount to some $13 \%$ of the revenue of the 26 cantons. Though this is double the amount of the equalization transfers, and though it may approach or exceed $20 \%$ of the total revenue in some cantons, it is still very small in international terms (Dafflon 2012).

Together, equalization and specific transfers (compensation and contributions) represent less than $20 \%$ of all cantonal revenue ( $6 \%$ and $13 \%$ ). Indirectly, this demonstrates the cantons' strong fiscal autonomy, because their tax revenue must, on average, cover up to $80 \%$ of the fiscal consequences of their spending decisions. There are significant differences between cantons. Only two of them receive less than $10 \%$ from the Confederation (Geneva and Basel Stadt). At the other extreme, seven cantons exceed the $30 \%$ threshold.

The cantons also receive a share of federal tax revenue (Ertragsanteile; parts de revenus) amounting, in particular, to $17 \%$ of the income tax on private individuals and on the profit and capital of legal entities and $10 \%$ of withholding tax. This is only about $6 \%$ of the total revenue of the 26 cantons, and so cantons have limited dependency on these transfers. Furthermore, this dependency is financial rather than institutional. Indeed, 


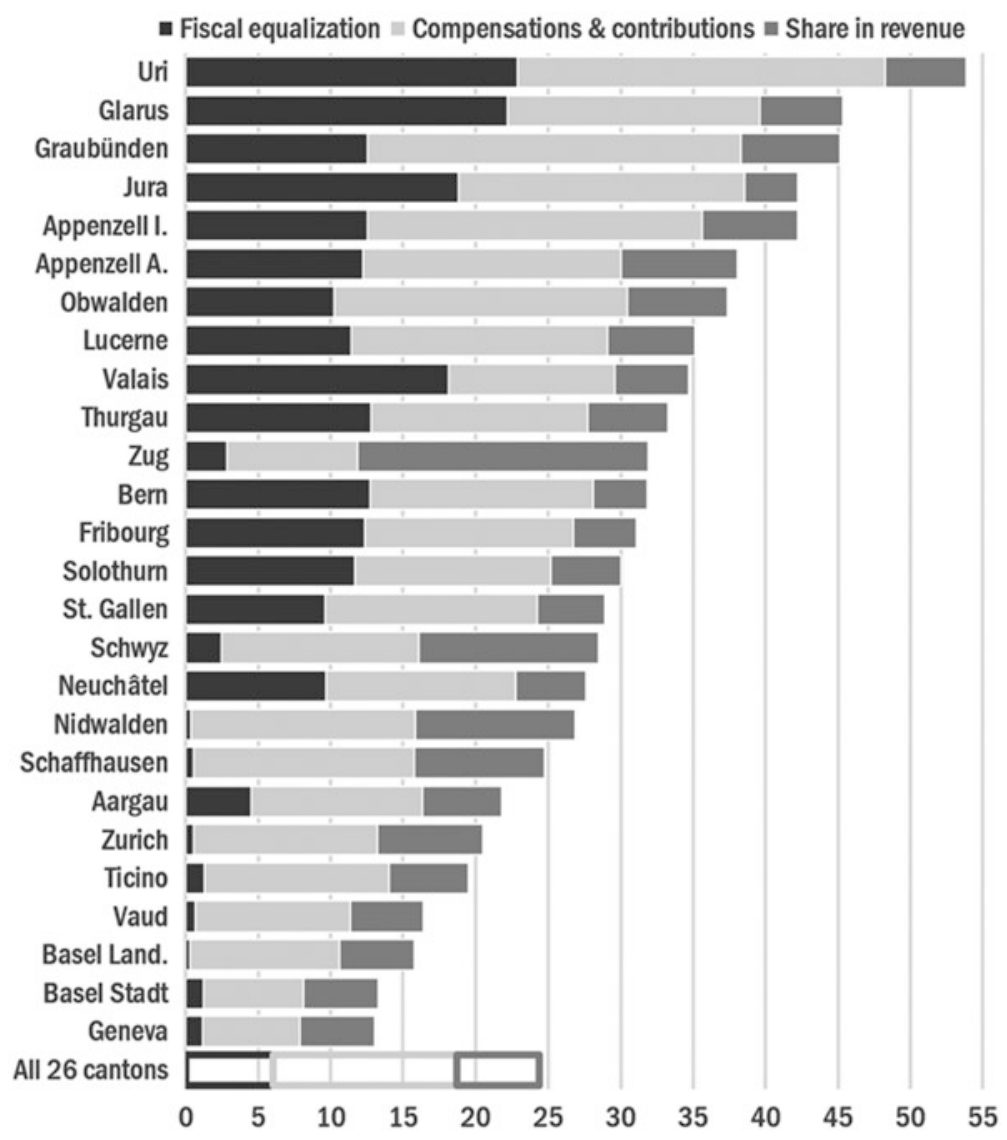

Fig. 17.3 Transfer dependency of Swiss cantons (transfers from the central government as a percentage of total cantonal revenue, 2015). (Note: Additional downloadable regular tables based on the Swiss governments' harmonized chart of accounts (FS Model). Fiscal equalization including cost compensation (account number 4620); compensations (4610) and contributions from the Confederation (4630); share in the tax revenue of the Confederation (4600); and total revenue (4) excluding extraordinary revenue (48). Source: Swiss Federal Finance Administration (2017). Switzerland's financial statistics for 2015. FS Model. Bern) 
the cantons obtained the right to these shares of federal tax revenue in return for the power they have given the central government to encroach upon their tax prerogatives. The Confederation is therefore obligated to provide these shares. Like the equalization transfers, these revenue shares are general grants since they may be spent at each canton's discretion.

Figure 17.3 underscores the claim that all in all cantonal financial dependence on the Confederation is quite small. On average, only a quarter of cantonal revenue comes from the central government and only a third of the cantons depend on the Confederation for more than a third of their revenue. Generally, the urban cantons (or those close to a large city) are the least dependent. The mountain cantons (Alps and Jura) are more strongly dependent, especially because of the larger equalization transfers they receive.

\subsection{Fiscal Equalization at the Cantonal Level}

Cantons have also introduced internal fiscal transfer and equalization systems in order to reduce the inequalities between municipalities within the cantons. A further goal has been to guarantee that even the smallest communities are able to provide their citizens with at least a minimum level of public services. Here again, Swiss federalism and cantonal autonomy over finances means that cantons can themselves decide whether they want a system of fiscal equalization between their municipalities, and if so, how they want to design their system.

As a result, there are many different designs, although cantons all share the goal of reducing fiscal inequalities. Having said that, and inspired by the new national system, several cantons recently revised their fiscal equalization systems, the canton of Valais even adopted the entire design of the national system.

Transfers to the municipalities tend to be less earmarked so that the municipalities may spend the funds at their discretion. Furthermore, the ability of municipalities to influence the amounts they receive or that they must pay has been reduced or eradicated. Indeed, what they could previously put into play, such as their tax rates, has been removed from the calculation formulas used in establishing the levels of the transfers. Most cantons have also introduced a clear separation between the equalization of resources and the cost compensation. Kübler and Rochat (2016) note that while these equalizing systems reduce inequalities that exist between Swiss municipalities, they do not eliminate them completely. 
This is because the equalization transfers are essentially horizontal ( $60 \%$ of the total). The amounts paid by the financially strong municipalities are redistributed to those which are financially weak, either directly or indirectly through a cantonal equalization fund. The cantons finance cost compensation for the benefit of those municipalities which face structurally higher costs than do other municipalities. The amounts redistributed each year from canton to municipality are quite large, reaching 5 billion $\mathrm{CHF}(0.8 \%$ of GDP) in 2013 . The equalization effort is smaller in the French-speaking Swiss cantons than in the Germanspeaking ones (Rühli et al. 2013).

\subsection{RoOm For Improvement In THE CANTONAL Equalization Systems}

Rühli et al. (2013) evaluated the cantonal equalization systems according to various criteria: basic structure, extent of the redistribution, and the incentives contained in the transfers. The authors found shortcomings in several cantons, but especially in Graubünden, Solothurn, St. Gallen, and Ticino. The best practices were in Glarus and Fribourg. In general, the shortcomings at the cantonal level are similar to those at the national level.

One shortcoming stems from the minimum allocation guaranteed to the financially weaker municipalities; it corresponds to the horizontal portion to the left of the dark solid curve in Fig. 17.2. Basically, it involves a marginal clipping rate of $100 \%$ because in this zone, an increase in the resource potential of the municipalities is wholly canceled by the corresponding decrease in the equalization transfers received. Under these conditions, many financially weak municipalities have little incentive to improve their fiscal situation on their own. This is frequently also a reason municipalities do not merge, since even if they are financially weak, the equalization scheme provides them with enough resources to carry out their basic tasks. The largest problems arise in the German-speaking part of Switzerland where several cantons use high minimum allocations (e.g., the resource index after equalization is higher than 90).

A second shortcoming is that the tyranny of the majority is all the more nagging, as cantonal systems largely rely on solidarity between municipalities when it comes to the horizontal transfers. Yet the municipalities which benefit from equalization are often more numerous than the contributing municipalities. This problem exists because cantons are not infrequently 
made up of many rural municipalities with few resources and a handful of wealthy municipalities which inflate the resource indices. There is a resulting power imbalance: the larger group — the financially weak municipalities — directs decision-making to their profit (by obtaining, e.g., increased equalization transfers).

A third shortcoming stems from the existence of a "neutral zone" in the cantonal equalization scale. To reduce the solidarity efforts of the financially well-off municipalities, cantons have often introduced an interval in the resource index, usually between 80 and 100, and municipalities situated there no longer receive any equalization transfers. This neutral zone does not exist in the national equalization scale.

This zone, in Fig. 17.2, corresponds to a situation in which the dark solid curve of the equalization scale would merge with the line of the fully ineffective scheme. The effect of introducing this kind of zone is to reduce the number of municipalities benefitting from equalization transfers and re-calibrate the power balance. It also makes it possible to lower the total amount of the transfers, since municipalities located in the neutral zone do not receive equalization transfers. Nevertheless, introducing this zone creates an inconvenient break in the equalization scale, making it less transparent and less intelligible. Because of this break in the slope, transfers to the municipalities with an index that is close or within the neutral zone may be unstable and change from one year to the next. Furthermore, the municipalities below the neutral zone may have an incentive to avoid carrying out reforms so as not to enter it.

\subsection{CONCLUSION}

Opportunities to improve both the national and the cantonal transfer and equalization systems exist, and efforts at improvement vary depending on the fiscal situation of the governments. Economic crises, international competition over business taxes, migration, and the aging of the population are all factors which challenge the balance that, until now, has existed.

All the same, considerable progress has been made over the last decade. The contradictions between redistribution transfers and allocation transfers have greatly decreased, and governments can no longer directly influence the amounts they receive or must pay by, for example, manipulating their tax rates. Reforms to the equalization systems have also made it possible to decrease the effects of tax competition. They indirectly ensure that tax competition between both cantons and municipalities can continue to exist, but within acceptable and accepted limits. 
These successes demonstrate that in Switzerland, notwithstanding the existence and the power of the tools of direct democracy, ambitious structural reforms involving numerous stakeholders remain possible. This obviously involves political strategizing, that is reflected in the introduction into the federal system - for a limited time - of compensation for hardship cases. And one must regard the recourse to a tyranny of the majority by governments which benefit from the transfers over the governments which finance the transfers as a necessary evil.

Despite, or thanks to, this tyranny, Switzerland has established rules meant to ensure fiscal equalization between its governments at all levels. These rules guarantee a certain automatism and a regularity to equalization flows, and by the same token, no discretionary decisions to give subsidy grants to decentralized municipalities - and no way for the wealthiest communities or cantons to ignore those political entities which are worse off than them.

\section{REFERENCES}

Dafflon, B. (2012). Les transferts financiers entre collectivités publiques. In A. Ladner, J.-L. Chappelet, Y. Emery, P. Knoepfel, L. Mader, N. Soguel, \& F. Varone (Eds.), Manuel d'administration publique suisse (pp. 661-678). Lausanne: PPUR.

Federal Council. (2014). Wirksamkeitsbericht 2012-2015 des Finanzausgleichs zwischen Bund und Kantonen. Bern: Schweizerische Eidgenossenschaft.

IMF (International Monetary Fund) Statistics Department. (2014). Government finance statistics manual 2014. Washington, DC: International Monetary Fund.

Kübler, D., \& Rochat, P. E. (2016). 'Tamed Tieboutianism' and spatial inequalities in Swiss metropolitan areas. In J. M. Sellers, M. Arretche, D. Kübler, \& E. Razin (Eds.), Inequality and governance in the metropolis: Place equality regimes and fiscal choices in eleven countries (pp. 107-124). London: Palgrave Macmillan.

OECD (The Organisation for Economic Co-operation and Development). (2015). OECD economic surveys: Switzerland 2015. Paris: OECD Publishing.

Rühli, L., Frey, M., \& Frey, R. L. (2013). Irrgarten Finanzausgleich. Wege zu mehr Effizienz bei der interkommunalen Solidarität. Zürich: Avenir Suisse. 
Open Access This chapter is licensed under the terms of the Creative Commons Attribution 4.0 International License (http://creativecommons.org/licenses/ by $/ 4.0 /$ ), which permits use, sharing, adaptation, distribution and reproduction in any medium or format, as long as you give appropriate credit to the original author(s) and the source, provide a link to the Creative Commons license and indicate if changes were made.

The images or other third party material in this chapter are included in the chapter's Creative Commons license, unless indicated otherwise in a credit line to the material. If material is not included in the chapter's Creative Commons license and your intended use is not permitted by statutory regulation or exceeds the permitted use, you will need to obtain permission directly from the copyright holder.

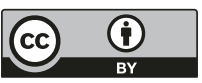

